\title{
A biblioteca alemã de João Guimarães Rosa
}

\author{
Daniel R. Bonomo ${ }^{1}$
}

\begin{abstract}
This article results from a research carried out between April and June of 2010 in the Instituto de Estudos Brasileiros at the Universidade de São Paulo, in which a complete list of titles related to the German language and culture was collected from João Guimarães Rosa's personal library. Alongside a description of the procedures taken, we offer a comment on some of the most important aspects of the material analysed, including its recurrent themes and features, such as the marginalia found in volumes by authors like Nietzsche, Kafka and Erich Auerbach, as well as on the general context of Guimarães Rosa's German readings. We intend to contribute to the studies of Guimarães Rosa's literary sources, and also to throw light on an object that may be of future interest within the German studies in Brazil.
\end{abstract}

Keywords: Guimarães Rosa's personal library; Guimarães Rosa's German readings and sources; Guimarães Rosa's marginalia.

Resumo: O artigo resulta de pesquisa realizada entre os meses de abril e junho de 2010 no Instituto de Estudos Brasileiros (USP) e apresenta a listagem completa dos títulos pertencentes à biblioteca de João Guimarães Rosa que de algum modo se relacionam à língua e cultura alemãs. Descrevemos nosso procedimento e procuramos privilegiar alguns aspectos do material estudado, elaborando uma introdução ao levantamento, comentando as presenças mais significativas, os temas recorrentes e a marginália encontrada em volumes de autores como Nietzsche, Kafka e Erich Auerbach, bem como o contexto da relação de Guimarães Rosa com as leituras alemãs. Intentamos contribuir no estudo de fontes da obra do autor de Grande sertão: veredas e desejamos por fim divulgar um objeto de provável interesse no âmbito dos estudos germanísticos brasileiros.

Palavras-chave: biblioteca pessoal de Guimarães Rosa; leituras e fontes alemãs de Guimarães Rosa; marginália de Guimarães Rosa.

Entre as bibliotecas pessoais reunidas e preservadas nas unidades do Instituto de Estudos Brasileiros da Universidade de São Paulo (IEB/USP), encontra-se o conjunto de livros e periódicos que pertenceu a João Guimarães Rosa. Como já se divulgou e evidências confirmam (como a presença de citações na obra e nos documentos do seu

\footnotetext{
${ }^{1}$ Doutorando em Língua e Literatura Alemã da Faculdade de Filosofia, Letras e Ciências Humanas da Universidade de São Paulo. Email: drbonomo@gmail.com
} 
espólio de autores e títulos que não se encontram atualmente na biblioteca do IEB), Guimarães Rosa pouco zelou pela manutenção do acervo dos livros adquiridos, lidos ou consultados durante a vida - daí que os exemplares no momento agrupados não representam a totalidade das suas leituras. Segundo Suzi Frankl SPERBER, a primeira a pesquisar na biblioteca do autor mineiro, Guimarães Rosa "[...] não tinha apego aos livros como entidades físicas. Só conservou aquilo que lhe interessou mais: no momento da sua morte, a sua biblioteca continha só 2477 livros. Para sua famosa cultura era pouco" (1976: 16). Imagina-se, portanto, que tenha deixado livros nas cidades em que trabalhou como integrante do serviço diplomático (Hamburgo, Bogotá, Paris), bem como tenha emprestado outros de/para amigos e bibliotecas. Mas o número "reduzido" é também expressivo e encerra títulos importantes para a melhor compreensão dos campos de interesse e das práticas de leitura do autor de Corpo de Baile.

A biblioteca de Guimarães Rosa dispõe hoje de aproximadamente 2900 livros e periódicos. $^{2}$ Os livros somam perto de 2770 volumes (o número de títulos é um pouco mais reduzido). ${ }^{3}$ Como a diversidade dos títulos dificulta a apreensão do conjunto, contribuímos, aqui, com o levantamento de uma das faces da biblioteca, mais precisamente a que volta seu interesse, em sentido amplo, para a cultura e língua alemãs. Nosso procedimento foi consultar as fichas de todos os títulos da biblioteca e reunir aqueles de autores de língua alemã (livros em alemão ou traduzidos para outros idiomas), bem como os de diversos autores traduzidos para a língua alemã, como também os que, de algum modo, passam por temas comuns ao recorte realizado. ${ }^{4} \mathrm{~A}$ pesquisa revelou aproximadamente 360 títulos do que nomeamos a "biblioteca alemã" de Guimarães Rosa, constatando que a língua alemã - depois das línguas portuguesa e francesa -, foi importante via de acesso do escritor a diversos autores, à leitura e estudo de temas do seu interesse e de línguas com que estava menos habituado. ${ }^{5}$

\footnotetext{
${ }^{2}$ Aproveitamos, aqui, para agradecer aos funcionários do IEB que nos auxiliaram nesta pesquisa.

${ }^{3}$ Há diversos títulos em edições compostas por mais de um volume como, por exemplo, o Brehms Tierleben, do zoólogo Alfred Brehm, que, na edição de Guimarães Rosa, estende-se por 12 volumes. A diferença entre o número de registros do IEB e o número apresentado por Suzi F. SPERBER provavelmente resulta da distinção entre volumes e títulos. Contudo, também notamos que há títulos registrados por Sperber cujo paradeiro é desconhecido, como um livro de Hermann Alexander von Keyserling (Del sufrimiento a la plenitud), por exemplo, que não está na coleção do IEB.

${ }^{4}$ Nossa pesquisa ocupou-se apenas dos livros de Guimarães Rosa, desconsiderando, neste momento, os periódicos.

5 Atribuímos a notícia da "biblioteca alemã" de Guimarães Rosa a Paulo Astor SoETHE (2005), que calculou aproximadamente 120 livros relacionados ao tema.
} 


\section{Guimarães Rosa e a língua e literatura alemãs}

O encontro de Guimarães Rosa com a língua alemã remonta à infância do escritor, conforme suas palavras:

Lá, em Minas Gerais, quando com nove anos de idade, muito espantei os meus, ao comprar, por mim mesmo, uma gramática alemã, para estudá-la, sozinho, sentado à beira da calçada, nos intervalos de jogar, com outros meninos, football de rua. Só foi isso por inato amor às palavras recortadas de exatas consoantes: tais como Kraft e Sanft, Welt e Wald, e Gnade e Pfad e Haupt e Schwung e Schmiss. Do que, depois, querer estudar medicina também em livros alemães, aproximar-me de Schiller, Heine, Goethe, e namorar, de preferência, as louras moças de origem alemã. (2003: 324)

A mudança para Hamburgo, em 1938, como funcionário do corpo diplomático, aproximaria o escritor do idioma. ${ }^{6}$ Muitos dos livros de Guimarães Rosa em língua alemã são desse período (ou comprados nesse período), como demonstra nossa listagem. Mais tarde, em entrevista a Günter Lorenz, em janeiro de 1965, o autor afirmaria:

Conheço bastante bem a literatura alemã. Por exemplo, o Simplicissimus é para mim muito importante. Amo Goethe, admiro e venero Thomas Mann, Robert Musil, Franz Kafka, a musicalidade de pensamento de Rilke, a importância monstruosa, espantosa de Freud. Todos estes autores me impressionaram e me influenciaram muito intensamente, sem dúvida. (apud LORENZ 1973: 344-45)

A fala integra a famosa e bastante escorregadia conversa de Guimarães Rosa com Lorenz. Não insistiremos nas suspeitas - aqui pouco importam -, mas verificamos, simplesmente, inexistir qualquer exemplar de Robert Musil em sua biblioteca; também há muito pouco de Freud, Kafka e Thomas Mann, apesar da influência declarada. Entretanto, de Goethe e Rilke há títulos importantes, bem como se encontra o

\footnotetext{
${ }^{6}$ Remetemos ao estudo de Paulo A. SOETHE que considera a relação complexa de Guimarães Rosa com a língua e cultura alemãs, bem como sua manifestação na obra do escritor (os "contos alemães" de Ave, palavra): "A simpatia pela língua e cultura da Alemanha (que entendo ser sincera e intensa em Rosa) não se deve a uma admiração ingênua e cega, que comentadores lhe atribuem de maneira quase leviana, mas sim a uma constatação das ambivalências da herança cultural e histórica daquele país, algo que desperta nele um misto de crítica discreta (por via irônica) e espelhamento (não raro sob o signo da autocomiseração)" (2005: 289).
} 
Simplicissimus, de Grimmelshausen. ${ }^{7}$ As presenças ou ausências no espólio do IEB, contudo, dizem pouco; este é um passo inicial: constatamos um corpo desigual de autores e títulos e uma variedade grande nas áreas de interesse. Para o futuro, permanece a tarefa de investigar o que efetivamente dialoga de maneira fecunda com a obra de Guimarães Rosa ou não.

Como a listagem da biblioteca alemã sugere, a língua alemã possibilitou o acesso de Guimarães Rosa a assuntos diversos: há livros de mineralogia e mapas astronômicos, equitação e jogos diversos, vestuário, música e artes plásticas, bem como estão presentes a medicina e a psicologia (incluindo estudos de hipnose, magnetismo e mesmerismo), a geografia e a política, a história e a arqueologia. Rosa utilizou-se também do alemão para a leitura de guias de locais como Berlim, Hamburgo, BadenBaden, Budapeste, Copenhague, Estocolmo, Florença, Roma e Londres. Aproximou-se ainda, por meio de dicionários, métodos e livros didáticos alemães, de línguas como o árabe (variantes síria e egípcia), finlandês, grego (antigo e moderno), hebraico, japonês, lituano, mandarim, russo e sueco.

Em nosso recorte, a literatura ocupa, segundo o critério linguístico, dois segmentos: a literatura de língua alemã (em alemão ou traduzida para outras línguas) e a de outras línguas traduzidas para o alemão. Destas, há desde os gregos até os modernos; daquelas, o arco não é menos amplo e vai das antigas sagas germânicas a autores do século XX. Devemos considerar, no entanto, a pessoalidade do conjunto, imaginando que as escolhas não se orientam apenas pela representatividade dos títulos no interior do cânone, mas sobretudo pelas inclinações do escritor, que, por sua vez, não são conhecidas somente por meio da apreciação de exemplares da sua biblioteca (muito menos por meio de parte dela). Afinal, como em qualquer coleção, há muitos volumes sem marcas de leitura, o que não significa, necessariamente, maior ou menor interesse por essas obras, como também o exame da marginália dos livros de fato lidos não permite conclusões inequívocas. A relação de Guimarães Rosa com os livros de sua biblioteca supõe algo mais complexo - não de todo determinável - e a noção de que atravessar um texto do escritor é também, de algum modo, ser atravessado por suas

\footnotetext{
${ }^{7}$ A edição de Guimarães Rosa não contém o texto completo do Simplicissimus. Sobre a relação da narrativa alemã seiscentista com o Grande sertão: veredas há ensaio de Marcus V. Mazzari (cf. bibliografia).
} 
leituras, o que não é novidade para a crítica, como também não é característica que se aplicaria com exclusividade ao tipo de prosa do autor de Grande sertão: veredas.

Uma idéia geral da coleção, como a compreendemos, privilegiando alguns nomes, sugere o valor do conjunto: as leituras alemãs de Guimarães Rosa iniciam em Homero, cuja Ilíada está em muitas páginas comentada. ${ }^{8}$ Dos gregos há também Ésquilo e a Batracomiomaquia (Tierepos, conforme a anotação de Guimarães Rosa); dos latinos há Petrônio, Marcial, Tibulo e a Germânia, de Tácito (em língua portuguesa). E, ainda no campo dos antigos, há edições alemãs de narrativas chinesas, das Mil e uma noites e uma reunião de sagas dinamarquesas de Saxo Grammaticus (autor mencionado em "O recado do morro"), bem como novelas italianas renascentistas e o Heptamerão, de Margarida de Navarra. Notamos também a presença de obras como a Kalevala, epopéia finlandesa, um número significativo de peças de Ibsen e as memórias de Casanova. E talvez surpreenda a alguém verificar a relação de autores dinamarqueses: além do mencionado Saxo Grammaticus, há Hans Christian Andersen, Carl Ewald, Herman Bang, Johannes Vilhelm Jensen, Svend Fleuron e Gunnar Gunnarson, que, apesar da origem islandesa, escreveu, sobretudo, em danês.

Da literatura de língua alemã na biblioteca de Guimarães Rosa há desde uma reunião de sagas antigas ou um texto como o Meier Helmbrecht (em francês), passando pela tradução luterana do texto bíblico, por Grimmelshausen e Angelus Silesius ( $O$ peregrino querubínico), até os autores clássicos e românticos dos séculos XVIII e XIX: livros de Lessing, Herder, Goethe, Schiller, Jean Paul, Novalis, Hoffmann, Kleist, Jacob e Wilhelm Grimm, Heine e Adelbert von Chamisso. Também se encontram representados os nomes heterogêneos de Willibald Alexis, Hebbel, Gustav Freytag, Theodor Storm, Conrad von Bolanden, Wilhelm Raabe, Sacher-Masoch, Agnes Sapper e Gustav Meyrink. ${ }^{9}$ Dos autores modernos mais importantes há um número considerável de títulos de Rainer Maria Rilke, além da presença tímida de Thomas Mann, Kafka, Hermann Broch, Franz Werfel e Ernst Jünger (um título para cada um). ${ }^{10}$ Autores menos conhecidos no Brasil, como Franz Blei, Wilhelm Schmidtbonn, Werner

\footnotetext{
${ }^{8}$ Sobre as leituras de Homero por Guimarães Rosa há estudo de Ana Luiza Martins CosTA (1997-98).

${ }^{9}$ Em artigo sobre Meyrink (junho de 1951) publicado n'O Jornal, Otto Maria CARPEAUX dizia: "Ficoume na memória uma conversa, há vários anos atrás, na Livraria José Olympio, com Guimarães Rosa que se admirara do destino póstumo do escritor austríaco Gustav Meyrink, mundialmente famoso por volta de 1920 - seu romance $O$ Golem foi traduzido para todas as línguas - e hoje esquecido [...]”.

${ }^{10}$ Há tese comparativa de Paulo Astor SOETHE que aproxima o Grande sertão: veredas da Montanha mágica, de Thomas Mann (1999).
} 
Bonomo, D. R. - A biblioteca alemã

Bergengruen, Hans Erich Nossack e Heinz Kükelhaus também têm lugar nas estantes de Guimarães Rosa.

Entre os pensadores não faltam Kant, Hegel, Schopenhauer, Nietzsche, Keyserling, Spengler e Karl Jaspers; Freud, Jung e nomes da psicologia e psiquiatria como Paul Helwig e Eugen Bleuler. E também há muito do pensamento religioso, desde o Tao Te Ching, de Lao Zi e os discursos de Buda, até os escritos de J. J. Ignaz von Döllinger e Odo Casel, contemplando a mística alemã do medievo tardio de Mestre Eckhart e a Imitação de Cristo, de Thomas von Kempen. E ainda poderíamos citar as presenças de Max Scheller, Martin Buber, Ortega y Gasset e Baltasar Gracián (em tradução de Schopenhauer). Guimarães Rosa, como Riobaldo, “bebe água de todo rio".

\section{O cômico e o Kafka de Guimarães Rosa}

Nossa pesquisa também contribui para o conhecimento das relações de Guimarães Rosa com o humour (o uso do termo estrangeiro era costume do próprio escritor). A presença do cômico é fundamental desde os textos do Sagarana e observável em aspectos da sua ficção, como a disparidade de algumas escolhas linguísticas, a caracterização burlesca de personagens, o tratamento desencontrado de alguns diálogos e o engendramento de situações pouco prováveis. ${ }^{11}$ Mais evidentes em uma ou outra narrativa, as configurações do cômico ainda contam com a reflexão de cunho teórico do autor de Tutaméia, como atestam os "prefácios" do livro, sobretudo "Aletria e hermenêutica", espécie de poética em que a "estória, às vezes, quer-se um pouco parecida à anedota" (1969: 03). Se o anedótico tem, portanto, lugar de destaque na obra de Guimarães Rosa, não surpreende que o tratamento do assunto acompanhe o autor desde muito antes. Nas anotações do período hamburguês, ${ }^{12}$ ou seja, aproximadamente três décadas antes da

\footnotetext{
${ }^{11}$ Recentemente (2009), publicou-se na França o artigo de Nilce SANT'ANNA MARTINS, num volume duplo de revista dedicada ao escritor, em que a pesquisadora propõe uma definição para o tipo de humor observado em Guimarães Rosa: "O humorismo rosiano não é do tipo sarcástico, mordaz, corrosivo, impiedoso; é, geralmente, de tom ameno, jovial, bonachão: focaliza o ridículo, o extravagante, o despropositado, o insólito risível, o "estúrdio" (para usar um termo do agrado do escritor), com tolerância, sem a invectiva, a revolta, a indignação, a intenção moralista de castigar os costumes que são predicados da sátira. É um humorismo que se prende mais ao bom-humor, à graça, à espirituosidade do que ao mauhumor, ao azedume, ao rancor".

12 Referimo-nos ao "diário de Hamburgo", "diário alemão" ou "diário de guerra", títulos comumente utilizados para identificar as anotações de João Guimarães Rosa entre 1939 e 1942. O documento pertence ao Fundo Henriqueta Lisboa, integrante do Acervo de Escritores Mineiros, da UFMG. Sobre o material há estudo de Georg OTTE, bem como matérias publicadas na imprensa (cf. bibliografia).
} 
publicação, em vida, do seu último livro, encontram-se algumas das primeiras versões de um conteúdo que seria aproveitado nas Terceiras estórias. Aparecem listadas, por exemplo, sob o tema da "abstração", a anedota do garoto perdido dos pais ("viram, por aí, um homem e uma mulher sem um meninozinho assim como eu?"), as definições do nada ("um balão, sem pele") e da vitrola ("você sabe o que é uma máquina de costura? pois a vitrola é muito diferente..."), a explicação do "telégrafo-sem-fio" e a referência à sua existência pré-histórica. Conforme indicação do próprio Guimarães Rosa, a definição do aparelho de mensagens como um cachorro bassê, "tão comprido, que a cabeça está no Rio e a ponta do rabo em Minas": "Se se belisca a ponta do rabo, em Minas, a cabeça, no Rio, pega a latir..." (esta a definição do telégrafo, pois o "telégrafosem-fio" seria o mesmo, "mas sem o corpo do cachorro"); a definição do aparelho teria origem na leitura dos livros de Peter Purzelbaum, Vom Kommiss, Kaczmarek und den Maikäfern ou Der fröhliche Kommiss, que são coleções de anedotas militares (apenas seriam substituídas as localidades de Berlim e Dresden por Minas Gerais e Rio de Janeiro).

No contexto medonho do conflito iniciado em 1939, as anotações e recortes de anedotas publicadas na imprensa convivem no diário do período com as notícias de bombardeios e da política de ódio e exclusão nazistas. ${ }^{13}$ Exemplo é a descoberta de Christian Morgenstern, em anotação de dezembro de 1940: “Os Hahn convidaram-me para jantar (vigília de Natal). Peru, etc. Contei anedotas de portugueses; em troca, revelaram-me Christian Morgenstern (Alle Galgenlieder) [...]". Como os livros de Purzelbaum, também o de Morgenstern se encontra no acervo do IEB. E também muitos outros que dão uma ideia da dimensão do seu interesse: uma versão da história de Till Eulenspiegel, espécie de personagem picaresco da tradição alemã; uma coleção de desenhos satíricos dos mitos gregos intitulada Heiterer Olymp; uma antologia de anedotas médicas reunidas por Eduard Stemplinger; uma reunião de textos irônicos de Peter Bamm, publicados na imprensa; os "versos morais e imorais" de Fred Endrikat; anedotas de Hamburgo por Erwin Garvens e o Klein Erna, de Vera Möller; uma coletânea de textos humorísticos de autores variados da literatura alemã, organizada por

\footnotetext{
${ }^{13}$ Sobre o tema da Segunda Guerra Mundial damos notícia de um conjunto de livros cuja contribuição para o estudo da relação de Guimarães Rosa com os problemas do período é certa. Podemos citar a presença da obra de Gustave Gilbert sobre os Julgamentos de Nuremberg, por exemplo; também há o livro sobre Hitler de Hermann Rauschning e o diário de William Shirer, correspondente em Berlim da Columbia Broadcasting System (CBS), todos com marcas expressivas de leitura.
} 
Bonomo, D. R. - A biblioteca alemã

Hans Balzer; e, por fim, o livro de anedotas de Wilhelm Scholz, no qual encontramos a possível fonte para uma passagem de "Nós, os temulentos", também um dos "prefácios" de Tutaméia. No livro de Scholz, a anedota leva o título de "Er wartet", "Ele espera", formulando-se da seguinte maneira:

Ein Betrunkener Soldat steht am Laternenpfahl und hält sich fest. Ein Schutzmann kommt und fragt ihn: Was machen Sie denn hier?

Die ganze Stadt dreht sich um mich. Nun warte ich, bis die Kaserne kommt, und dann gehe ich hinein. (1938: 180) ${ }^{14}$

Reformulada com a propriedade do estilo rosiano e conformada ao caso do bêbado protagonista do terceiro "prefácio" de Tutaméia, a semelhante anedota:

E, hora depois, peru-de-fim-de-ano, pairava ali, chave no ar, na mão, constando-se de tranquilo terremoto. - Eu? Estou esperando a vez da minha casa passar, para poder abrir... Meteram-no a dentro (1969: 104).

Mas o aproveitamento de material alheio é apenas uma das faces de um processo criativo de maior complexidade. A obra de Guimarães Rosa, como a de todo grande escritor, realiza diálogos os mais distintos, inclusive com assuntos e autores de uma literatura aparentemente distante da sua, como exemplifica sua relação com a ficção de Franz Kafka. Na entrevista a Günter Lorenz, Kafka é mencionado com admiração. Não se pode precisar, contudo, quais dos seus livros Guimarães Rosa conheceu e de fato leu; também não se pode, de modo detalhado, saber de que maneira apreciou o autor tcheco. A biblioteca do IEB guarda apenas um de seus livros: O processo, em tradução francesa. Neste se observa algo curioso: Guimarães Rosa cola um pequeno recorte de jornal no livro, na primeira página, em português, sem identificar a origem, com o seguinte comentário:

Num lugar pouco acessível, na revista flamenga Vlaamse Gids (números de setembro e outubro de 1954), publica H. Uyttersprot estudos originalíssimos sobre Kafka. O crítico não encontra nada de confusão e dificuldades nos contos e no Castelo, cujos originais Brod recebeu do próprio Kafka, isto é, na boa ordem das páginas. Difícil e confuso só é o Processo, cujos originais o próprio Brod pôs em ordem. Mas, parece, em ordem errada. O crítico esclarece a obra, propondo nova ordem dos capítulos: $1,4,2,3,5,6,9,7,8 \ldots 10$, havendo entre

\footnotetext{
${ }^{14}$ Nossa tradução: "Um soldado bêbado agarra-se a um poste de luz. Um policial se aproxima e pergunta: 'O que o senhor faz aqui?'/ 'Toda a cidade está girando à minha volta. Então estou esperando até que chegue o quartel para entrar”.
} 
os capítulos 8 e 10 uma lacuna. O resultado da releitura, conforme essa nova ordem dos capítulos, é realmente impressionante.

A polêmica e o interesse em torno da ordenação da narrativa de Kafka não bastaram, contudo, para que a leitura de Guimarães Rosa ultrapassasse o capítulo quinto (ou bastaram para que não o ultrapassasse?), e na ordem de Max Brod, conforme as páginas ainda fechadas do restante do volume atestam. O exemplar apresenta ainda uma única anotação no capítulo terceiro, quando o protagonista K. percorre os cartórios e há uma tentativa de conversa com outro acusado cujo fracasso apenas faz aproximar um guarda. A passagem, por algum motivo e momento indeterminados, prendeu a atenção de Guimarães Rosa, pois os "detalhes do incidente" estão sublinhados, como a caracterização do vigia, reconhecido "por um sabre cuja bainha, ao menos pela cor, era feita de alumínio", observado em seus "passos muito apressados, porém muito curtos, provavelmente regulados pela gota" (KAFKA 2001: 84). E os trechos sublinhados ainda são explicados por Guimarães Rosa à margem da página como os "detalhes realistas", demonstrando sua consideração do pormenor - talvez no intuito de observar a qualidade do realismo de Kafka, cuja prosa foi muitas vezes reduzida a seu efeito onírico. Porém não há mais anotações no volume e a leitura é interrompida; e não podemos identificar o que motivou semelhante abandono - as circunstâncias são provavelmente irrecuperáveis: talvez desinteresse, talvez uma espécie de incômodo, contrariando a admiração declarada (um pouco como a perturbação da leitura de Machado de Assis por Guimarães Rosa, verificada nos seus manuscritos do período hamburguês), pois Guimarães Rosa e Kafka não são escritores de inclinações similares nas escolhas dos temas e tons narrativos, embora talvez possam convergir na escrita labiríntica dos seus romances. $^{15}$

\footnotetext{
${ }^{15}$ A identificação da literatura de Kafka com o labirinto, além de elucidativa, é recorrente e lugar-comum. No caso de Guimarães Rosa, o seguinte comentário de Willi Bolle vem ao caso: "Utilizando as categorias do estudo de Manfred Schmeling sobre o discurso labiríntico [...] podemos distinguir em Grande sertão: veredas um aspecto teseico e um aspecto dedálico. Assim como o seu mítico precursor Teseu, também Riobaldo é um herói errando (itinerando) através do espaço labiríntico. Já do ponto de vista do seu criador, o escritor João Guimarães Rosa, a questão do labirinto se coloca num nível mais técnico. Assim como o labirinto de Creta foi um artefato inventado pelo mítico arquiteto Dédalo, também o labirinto verbal de Grande sertão: veredas é algo construído, uma ordem artificial" (2004: 81). Dar continuidade à relação que surge a partir do labirinto enquanto discurso e imagem sugestiva é problema para outra ocasião. Apenas notamos que a aproximação dos dois autores nos fornece de imediato uma distinção, ainda que superficial, na configuração metafórica: o labirinto do sertão rosiano assemelha-se mais a um labirinto a céu aberto, oscilante, entre a secura e a vereda, mas algo esperançoso, ao passo que o labirinto kafkiano é mais comumente opaco e opressor. Nos dois casos, porém, insistem a ameaça do ambiente e as limitações próprias às personagens. Entenda-se, ainda, que o labirinto, como já bem notou
} 
Se há desinteresse ou algo parecido na leitura de Kafka por Guimarães Rosa, isso pouco acrescenta à investigação, pois notamos a possibilidade de interferência na ideia que a literatura do autor tcheco frequentemente desperta - o contra-senso, o despropósito -, como ocorre no prefácio mencionado de Tutaméia. Nesse texto, Guimarães Rosa utiliza-se da chave humorística para a interpretação do que considera episódio absurdo à maneira de Kafka:

Siga-se, para ver, o conhecidíssimo figurante, que anda pela rua, empurrando sua carrocinha de pão, quando alguém lhe grita: - "Manuel, corre a Niterói, tua mulher está feito louca, tua casa está pegando fogo!..." Larga o herói a carrocinha, corre, voa, vai, toma a barca, atravessa a Baía quase... e exclama:

- "Que diabo! Eu não me chamo Manuel, não moro em Niterói, não sou casado e não tenho casa..." (RosA 1969: 04).

A anedota, que é forma simples e modelo para a compreensão da "estória" na obra de Guimarães Rosa, "pulo do cômico ao excelso", é também chave para uma compreensão particular de Kafka: "[...] ponha-se em frio exame a estorieta, sangrada de todo burlesco, e tem-se uma fórmula à Kafka, o esqueleto algébrico ou tema nuclear de um romance kafkaesco por ora não ainda escrito" (RosA 1969: 04).

\section{Exemplares de outras espécies}

O estudo da vida e comportamento dos animais sempre foi caro a Guimarães Rosa. A obra do escritor o comprova, bem como suas declarações enfatizam essa predileção. Sua biblioteca, por conseguinte - não somente no corte alemão -, confirma o que diz o pesquisador e revela algumas das fontes utilizadas no estudo do assunto para além da observação in loco. Como o terreno é amplo e escapa à nossa competência, limitamonos a mencionar alguma variedade como o Brehms Tierleben, obra capital da zoologia popular do século XIX e consultada pelo escritor em várias ocasiões; ou os livros de Carl Hagenbeck, conhecido mercador de animais e diretor do zoológico (Tierpark Hagenbeck) muito visitado por Guimarães Rosa em Stellingen, ao norte de Hamburgo. Há também a presença de escritores conhecidos por suas histórias em que protagonizam animais, como os dois exemplares de Paul Eipper e um de Ernest Thompson Seton

BARTHES, pode ser um "falso bom assunto", pertencendo melhor àquilo que nomeia "narratividade forte, incandescente" (2005: 250). 
(traduzido para o alemão); e há cientistas como os ornitólogos Oskar Heinroth e Helmut Sick, que se naturalizou brasileiro e com sua pesquisa contribuiu, inclusive, para a tradução do Grande sertão: veredas, como se observa na leitura da correspondência de Guimarães Rosa com seu tradutor alemão, Curt Meyer-Clason. ${ }^{16}$

Do exame de outros exemplares, destacamos a leitura de alguns teóricos da literatura. Há estudos em língua alemã das literaturas russa, espanhola, francesa, inglesa, americana e títulos importantes como o Mimesis, de Auerbach, e Literatura européia e Idade Média latina, de Ernst Robert Curtius. Neste, cuja edição brasileira conta com a colaboração do amigo Paulo Rónai, Guimarães Rosa não se deteve, segundo os indícios do exemplar. No entanto, percorreu melhor o livro de Auerbach (em tradução para o espanhol), sublinhando alguns trechos - embora interessantes, são ainda marcas discretas e que não podem medir, portanto, muito do seu interesse por um estudo da representação literária "determinada sociologicamente segundo o momento histórico" (AUERBACH 2002: 409). ${ }^{17} \mathrm{O}$ estudo da marginália, neste caso, auxilia no entendimento da obra do próprio Guimarães Rosa, tal como o escritor parece querer concebê-la, no seu misticismo particular, quando, por exemplo, sublinha trecho sobre as intenções artísticas de Flaubert:

Elas desembocam numa teoria que é, em última análise, mística, mas que repousa, na prática, como todo verdadeiro misticismo, sobre a razão, a experiência e a disciplina; uma teoria da submersão nos objetos da realidade que se esquece de si mesma, através da qual estes objetos seriam transformados ( par une chimie merveilleuse) e evoluiriam até atingir a maturidade verbal. Desta forma, os objetos preenchem inteiramente o escritor, ele se esquece a si próprio, o seu coração serve-lhe tão-somente para sentir o dos outros; e quando este estado, atingível somente pela violência de uma paciência fanática, for alcançado, a expressão linguística plena, que ao mesmo tempo apanha integralmente o objeto em questão e o julga imparcialmente, apresenta-se de per si: os objetos são vistos como Deus os vê, na sua verdadeira realidade. (AUERBACH 2002: 436) ${ }^{18}$

\footnotetext{
${ }^{16}$ Cf. as cartas de 22 de janeiro, 14 de fevereiro, 11 de março e 11 de maio de 1964, publicadas no volume de sua correspondência (2003).

17 Guimarães Rosa procurou preservar-se das manifestações de natureza teórica, bem como evitou pronunciar-se relativamente a outros autores. Seus prefácios no Tutaméia são casos raros de cruzamento do ficcional com a reflexão teórica sobre a literatura. Numa dissertação recente, Mônica F. Rodrigues GAMA (2008) chama a atenção para um manuscrito presente nos rascunhos de "Sobre a escova e a dúvida" em que se reconhecem os nomes de Joyce, Kafka, Faulkner e Lukács. No contexto, como demonstra o prefácio publicado, utiliza-se da ironia que o tratamento de um personagem-escritor, visitante e pedante, permite, agrupando nomes díspares como representantes de uma literatura que fosse a última palavra nos meios cultos, por exemplo.

${ }^{18}$ Os trechos destacados estão sublinhados por Guimarães Rosa.
} 
No mesmo livro, mais um trecho sublinhado talvez seja compreensível como um comentário à própria obra. Porém, dessa vez, não se apontaria, como no caso anterior, para o método de trabalho e sua concepção do valor da palavra precisa, senão para o efeito confuso que uma obra de peso promove na sua avaliação pública, como foram os casos de Sagarana e Grande sertão: veredas (como foi o caso dos Goncourt no século XIX, conforme Auerbach): “[...] a originalidade da obra nova e importante faria com que o público, ainda não acostumado à sua forma de expressão, se sentisse primeiramente apenas confuso e inquieto, e só pudesse acostumar-se à nova linguagem formal gradualmente" (2002: 450).

O estudo da marginália oferece a possibilidade da leitura de um autor no outro e por meio do outro. Alguns cruzamentos são mais claros e os oferecem a própria obra de Guimarães Rosa e seus depoimentos mais conhecidos e melhor registrados; outros surgem do trabalho de pesquisa e da intuição do leitor. Sabemos, por exemplo, da religiosidade do escritor (notável também em nossa listagem) ou de sua preferência por filósofos como Plotino ou Bergson. Porém contribuem igualmente suas relações com outros nomes. Afinal, constatar, por exemplo, que o escritor leu com interesse parte da obra de Nietzsche (em tradução francesa) deve ser também revelador. Há nesse encontro uma dose de conflito, uma vez que o polêmico é a expressão do desacordo de algumas poucas notas de Guimarães Rosa. Na leitura de Humano, demasiado humano, por exemplo, em face de um aforismo como o 129, nomeado "Liberalidade proibida", e que afirma não haver "[...] no mundo amor e bondade bastantes, para que ainda possamos dá-los a seres imaginários" (NIETZSCHE 2009: 92), Guimarães Rosa escreve uma única palavra (e o sinal da ênfase): “erro!". No mesmo livro, quando o filósofo alemão expõe suas considerações a respeito da "origem da fé", Guimarães Rosa manifesta uma vez mais sua discordância: o fragmento considera a fé enquanto hábito de um "espírito cativo" e vincula sua prática ao exercício de um costume em que não regem os fundamentos de qualquer razão: "[...] como alguém que, nascendo numa região vinícola, torna-se bebedor de vinho" (NIETZSCHE 2009: 144). A última frase do aforismo é sublinhada por Guimarães Rosa: "Habituar-se a princípios intelectuais sem razões é algo que chamamos de fé” (NIETZSCHE 2009: 145). A frase leva um comentário curioso do escritor à margem: "Falso. V. m\% caso aos 14 anos. V. Saulo de Tharso. Há 
a fé à primeira vista". ${ }^{19}$ À fé como hábito, portanto, Guimarães Rosa opõe a fé adquirida por revelação, associando um episódio da sua vida pessoal (aqui um dado interessante para o estudo biográfico) à aparição de Jesus para Saulo. Nesse mesmo horizonte, poderíamos também recordar, do Grande sertão: veredas, o jagunço Joé Cazuzo, que,

[...] em arraso de um tirotêi [...] se ajoelhou giro no chão do cerrado, levantava os braços que nem esgalho de jatobá seco, e só gritava, urro claro e urro surdo: - "Eu vi a Virgem Nossa, no resplandor do Céu, com seus filhos de Anjos!..." Gritava não esbarrava. - "Eu vi a Virgem!...” Ele almou? (ROSA 1958: 20-21)

Mas o aproveitamento de Nietzsche por Guimarães Rosa não se faz apenas da observação de recusas. Ainda é possível identificar uma espécie de recorte no pensamento do filósofo a fim de esclarecer noções mais íntimas do universo rosiano. Um exemplo do procedimento é o que se lê à margem do fragmento intitulado "O que há de inocente nas chamadas más ações", em que se destaca o seguinte trecho: "O indivíduo pode, na condição que precede o Estado, tratar outros seres de maneira dura e cruel, visando intimidá-los: para garantir sua existência, através de provas intimidantes de seu poder" (NIETZSCHE 2009: 70). Ao lado do trecho, o escritor anota: "Cangaceiros" (que, na sua obra, são mais "jagunços"), dando nome à ideia que assume data e lugar novos. A transferência de um pensamento assim é, contudo, apenas um dos indícios que dão testemunho da diversidade dos diálogos que têm lugar no processo criativo de um escritor como Guimarães Rosa. Nos limites de um trabalho introdutório, procuramos dar um passo em direção a pesquisa mais ampla e que desenvolva a idéia segundo a qual na leitura da obra de João Guimarães Rosa - e nem tudo está nos livros... - são muitas as leituras.

\section{Referências bibliográficas}

Auerbach, Erich. Mimesis. A representação da realidade na literatura ocidental. Tradução de George Sperber. São Paulo, Perspectiva, 2002.

BARTHES, Roland. A preparação do romance I - da vida à obra. Tradução de Leyla Perrone-Moysés. São Paulo: Martins Fontes, 2005.

\footnotetext{
${ }^{19} \mathrm{O}$ sinal "m\%" é recorrente nos manuscritos de João Guimarães Rosa. Refere-se à sua própria pessoa e criações: trechos, frases e palavras de sua autoria, observações de toda ordem, sejam invenções, sejam apropriações de material alheio.
} 
Bolle, Willi. grandesertão.br. O romance de formação do Brasil. São Paulo, Duas Cidades; Ed. 34, 2004.

CARPEAuX, Otto Maria. Meyrink, escritor imperfeito. O Jornal, Rio de Janeiro, 03 de junho de 1951.

CostA, Ana Luiza Martins. Rosa, ledor de Homero. In: Revista USP 36, 1997-98, 4773.

Gama, Mônica F. Rodrigues. Sobre o que não deveu caber. Repetição e diferença na produção e recepção de Tutaméia. Dissertação de mestrado. FFLCH/USP, São Paulo, 2008.

KAFKA, Franz. O processo. Tradução de Modesto Carone. São Paulo, Companhia das Letras, 2001.

Lorenz, Günter W. Diálogo com a América Latina. Panorama de uma literatura do futuro. Tradução de Rosemary Costhek Abílio e Fredy de Souza Rodrigues. São Paulo, E. P. U., 1973.

Martins, Nilce Sant'Anna. O humor na obra de Guimarães Rosa. In: Plural Pluriel. Revue des cultures de langue portugaise 4-5, 2009.

MAZZARI, Marcus V. Figurações do mal e do maligno no Grande sertão: veredas. In: Estudos Avançados 22, 64, 2008.

NiETZSCHE, Friedrich. Humano, demasiado humano. Um livro para espíritos livres. Tradução de Paulo César de Souza. São Paulo, Companhia das Letras, 2009.

OтTE, Georg. O "diário alemão" de João Guimarães Rosa. In: Duarte, Lélia Parreira et. al. (ed.). Veredas de Rosa II. Belo Horizonte, PUC Minas, 2003, 285-90.

RosA, João Guimarães. Correspondência com seu tradutor alemão Curt Meyer-Clason (1958-1967). Rio de Janeiro, Nova Fronteira; Academia Brasileira de Letras; Belo Horizonte, Ed. da UFMG, 2003. Grande sertão: veredas. Rio de Janeiro, José Olympio, 1958. Tutaméia. Rio de Janeiro, José Olympio, 1969.

SoEthe, Paulo Astor. A imagem da Alemanha em Guimarães Rosa como retrato autoirônico. In: Scripta 17, 9, 2005, 287-301.

SOETHE, Paulo Astor. Ethos, corpo e entorno: sentido ético da conformação do espaço em Der Zauberberg $e$ Grande sertão: veredas. Tese de doutorado. FFLCH/USP, São Paulo, 1999.

SPERBER, Suzi Frankl. Caos e cosmos. Leituras de Guimarães Rosa. São Paulo, Duas Cidades; Secretaria da Cultura, Ciência e Tecnologia, 1976. 


\section{Anexo \\ Listagem dos títulos da biblioteca alemã de João Guimarães Rosa}

AESCHYLUS. Agamemnon. Tradução de Hans Wolzogen. Leipzig: Reclam, s. d.

AESCHYLUS. Das Totenopfer. Tradução de Hans Wolzogen. Leipzig: Reclam, s. d.

Aladdin und die Wunderlampe. Aus Tausend und eine Nacht. München: Hugo Schmidt, 1919.

ALMEIDA, Renato. Fausto: ensaio sobre o problema do ser. Rio de Janeiro: Briguiet, 1951.

ALEXIS, Willibald. Der falsche Woldemar. Vaterländischer Roman. Halle a. d. S.: Otto Hendel, s. d.

ANDERSEN, Hans Christian. Märchen. Berlin: Th. Knaur Nachf, 1938.

ANGELLOZ, Joseph-François (org.). Meisterwerke deutscher Lyrik. Paris: Presses Universitaires de France, 1947.

ARSENIEW, Nicolas von. Die russische Literatur der Neuzeit und Gegenwart. Mainz: Dioskuren, 1929. (margin.)

ASCHMIES, Michael. Metoula-Sprachführer. Litauisch. Berlin/Schöneberg: Langenscheidt, s. d.

ATKINSON, William Walker. Gedankenkraft im Geschäfts und Alltagsleben. Berlin: Psychologischer Verlag, s. d.

AUERBACH, Erich. Mimesis. La representación de la realidad en la literatura occidental. Tradução de I. Villanueva e E. Imaz. México: Fondo de Cultura Económica, 1950. (margin.)

BALZER, Hans (org.). Geister deutscher Heiterkeit. Stuttgart: Franckh'sche Verlagshandlung, 1934.

BAMM, Peter. Feuilletons. Stuttgart: Deutsche Verlags-Anstalt, 1949

BANG, Herman. Die vier Teufel. Berlin: Fischer, 1926.

BARTH, Willi. Metoula-Sprachführer. Neugriechisch. Berlin/Schöneberg: Langenscheidt, 1913.

BEHEIM-SCHWARZBACH, Martin. Das Buch vom Schach. Eine Darstellung und Anweisung für die Freunde des Spiels. Leipzig: Insel, s. d.

Bengalische Erzähler. Der Sieg der Seele. Tradução de Reinhard Wagner. Berlin: Wegweiser, s. d. (margin.)

BENSE, Max. Brasilianische Intelligenz. Eine cartesianische Reflexion. Wiesbaden: Limes, 1965.

BERGENGRUEN, Werner. Am Himmel wie auf Erden. Hamburg: Hanseatische Verlaganstalt, 1940.

BERGENGRUEN, Werner. Der Grosstyrann und das Gericht. Hamburg: Hanseatische Verlaganstalt, 1940.

BERGENGRUEN, Werner. Der letzte Rittmeister. München: Nymphenburger, 1952. 
BERGENGRUEN, Werner. Der spanische Rosenstock. Zürich: Arche, 1946.

BERGENGRUEN, Werner. Der Tod von Reval. Kuriose Geschichte aus einer alten Stadt. Hamburg: Hanseatische Verlaganstalt, 1939.

BERGENGRUEN, Werner. Die drei Falken. Dresden: Wilhelm Heyne, 1937.

BERGENGRUEN, Werner. Die Rittmeisterin. München: Nymphenburger, 1954.

Bericht der Diözesan-Abgeordneten an den hohen Regierungs-Rath des Kantons Aargau betreffend die Amtsenthebung des Herrn Eugen Lachat, Bischofs von Basel. Aarau: Albrecht, 1873.

Berlin und Umgebung. Mit Angaben für Automobilisten. Berlin: Grieben, 1936.

(Die) Bibel oder die ganze Heilige Schrift des Alten und Neuen Testaments. Tradução de Lutero. Stuttgart: Württembergische Bibelanstalt, 1961.

BINZER, Ina von. Os meus romanos: alegrias e tristezas de uma educadora alemã no Brasil. São Paulo: Anhembi, 1956. (margin.)

BISCHOFF, Joseph Eduard Konrad. Der Teufel in der Schule. Volkserzählung von Conrad von Bolanden. Freiburg im Breisgau: Herderische Verlagshandlung, 1896.

BLATTNER, Karl. Langenscheidts Taschenwörterbuch der russischen und deutschen Sprache. Berlin/Schöneberg: Langenscheidt, 1929.

BLEI, Franz; SOMOFF, Constantin. Das Lesebuch der Marquise. München: Hans von Weber, 1908.

BLEULER, Eugen. Lehrbuch der Psychiatrie. Berlin: Julius Springer, 1937.

BLÜMICH, Max. Aljechins Sieg. Leipzig: Leipziger Zeitung, s. d.

BOBERG, Torsten. Die seltsame Wolfsjagd des Lars Emerentius Renander und andere Erzählungen aus dem schwedischen Hochgebirge. Tradução de Ilse MenerLüne. Berlin: Safari, 1941.

BÖER, Friedrich. 750 Jahre Hamburger Hafen. Hamburg: Paul Hartung, 1939.

BÖHMIG, Ludwig. Zoologia I. Tradução de E. Fernández Galiano. Barcelona: Labor, 1926.

BÖRNER, Rudolf. Was ist das für ein Stein. Stuttgart: Franckh'sche Verlagshandlung, 1938.

BRANDT, Paul. Lebenskultur im alten Griechenland. Wien: Paul Aretz, 1925.

BREASTED, James Henry. Geschichte Aegyptens. Zürich: Phaidon, 1936.

BREHM, Alfred Edmund. Brehms Tierleben. Wien: Gutenberg-Verlag Christensen \& Co., 1926-28.

BRINCKMANN, Alfred. Schachmeister. Wie sie kämpfen und siegen. Leipzig: Hans Hedewigs Nachf, 1932.

BROCH, Hermann. Der Tod des Vergil. Zürich: Rhein, 1945. (margin.)

BRÖRING, Theodor. Metoula-Sprachführer. Nordchinesisch. Berlin/Schöneberg: Langenscheidt, 1914.

BRUHN, Wolfgang. Kostüm und Mode. Eine bunte Fibel. Leipzig: Staackmann, 1938.

BUBER, Martin. Die Geschichten des Rabbi Nachman. Frankfurt: Fischer, 1955. (margin.)

BUBER, Martin. I and thou. Tradução de Ronald G. Smith. New York: Charles Scribner's Sons, 1958. (margin.) 
BÜCKEN, Ernst. Wörterbuch der Musik. Leipzig: Dieterich'sche Verlagshandlung, 1940.

Budapest und Umgebung. Berlin: Grieben, 1937.

BÜDDEMANN, Werner. Welcher Stil ist das? Stuttgart: Franckh'sche Verlagshandlung, 1938.

BUDDHA. Die Reden Gotamo Buddhos. Tradução de Karl Eugen Neumann. München: Piper, 1924.

BURCKHARDT, Jakob C. Briefe. Fritz Kaphahn (org.). Leipzig: Dieterich'sche Verlagshandlung, 1929.

BURCKHARDT, Jakob C. Le Cicerone. Guide de l'art antique et de l'art moderne en Italie. Tradução de Auguste Gérard. Paris: Firmin-Didot, s. d. (margin.)

BUSCHAN, Georg Hermann Theodor. Die Völker Asiens, Australiens und der Südseeinseln. Berlin: Globus, s. d.

CASANOVA DE SEINGALT, Giacomo Girolamo. Erinnerungen aus galanter Zeit. Berlin: Wilhelm Borngräber, 1911.

CASEL, Odo. La veritable image de l'homme. Tradução de Maurice Lefèvre. Paris: Ch. Beyaert-Bruges, 1954.

CHAMISSO, Adelbert von. Peter Schlemihl's Wundersame Geschichte. Paris: Hatier, 1941.

CHRISTIE, Agatha M. C. Der Rote Kimono. München: Wilhelm Goldmann, 1955.

CLARAC, E. Deutsches Sprachbuch. Paris: Masson, 1937.

COLOMBIER, Pierre du. L'art allemand. Paris: Larousse, 1946.

CROY, Otto Roman. Fotomontage. Der Weg zu den Grenzen der Fotografie. Halle: Wilhelm Knapp, 1948.

CURTIUS, Ernst Robert. Literatura européia e Idade Média latina. Tradução de Teodoro Cabral. Rio de Janeiro: MEC/INL, 1957.

Dänische Heldensagen nach Saxo Grammaticus. HERMANN, Paul (org.). Jena: Eugen Diederich, 1925.

DAPONTE, R. (org.). Novellen der Renaissance. Wien: Heim, 1928.

DENCKER, Klaus Peter. Als Mensch unter Menschen. Hamburg, 1965.

DOEBLIN, Alfred. Les pages immortelles de Confucius. Paris: Corrêa, 1947.

DÖLLINGER, Johann Joseph Ignaz von. O Papa e o Concílio: a questão religiosa. Versão e introdução de Ruy Barbosa. São Paulo: Saraiva, 1930. (margin.)

(Die) dreizehnstöckige Pagode. Altchinesische Liebesgeschichten. Tradução de Franz Kuhn. Berlin: Steiniger, 1940.

Duden. Rechtsschreibung der deutschen Sprache und der Fremdwörter. Wiesbaden: Franz Steiner, 1949.

Duden. Der grosse Duden. Leipzig: Bibliographisches Institut, 1938.

DUFRESNE, Jean. Kleines Lehrbuch des Damenspiels. Leipzig: Reclam, 1884.

DUFRESNE, Jean. Lehrbuch des Schachspiels. Leipzig: Reclam, 1941.

ECKHART, Johann. Traités et sermons. Paris: Aubier, 1942. (margin.)

(Les) Efforts du Gouvernement Allemand et de ses Allies en faveur de l'Unité de l'Allemagne; 1955-1966. Ministére Fédéral des Affaires Étrangères, 1966. 
EHRENZWEIG, Stephen. Zoo. Berlin: Herbert Stuffer, 1930.

EIPPER, Paul. Du, liebe Katze! München: Piper, 1953.

EIPPER, Paul. Tiere sehen dich an. Berlin: Dietrich Reimer, 1929.

ELSNER, Wilhelm. Unvergängliche deutsche Lyrik. Hamburg: Hans von Hugo, 1947. (marg.).

ENDRIKAT, Fred. Höchst weltliche Sündenfibel. Moralische und „unmoralische“ Verse. Berlin: Buchwarte, 1940.

EPTING, Karl (org.). Poètes et penseurs. Paris: Fernand Sorlot, 1941. (margin.)

ERICH, Oswald Adolf. Deutsche Volkstrachten. Leipzig: Bibliographisches Institut, 1934.

EWALD, Carl Anton. Das Sternenkind und andere Geschichten. Stuttgart: Franckh'sche Verlagshandlung, 1927.

FESSLER, Julius; RUFF, Otto. Gasschutz. Gashilfe gegen Giftgase. Merkbüchlein für Laienhelfer bis zum Eingreifen des Arztes. Leipzig: Alwin Fröhlich, 1940. (margin.)

FISCHER, Ernst. The necessity of art. A marxist approach. Tradução de Anna Bostock. New York: Penguin, 1959. (margin.)

FLEURON, Svend. Katzenvolk. Köln: Eugen Diederichs Verlag, 1956.

FORST-BATTAGLIA, Otto. Die französische Literatur der Gegenwart - 1870-1927. Wiesbaden: Dioskuren, 1928.

FÖRSTER, Hans Walter. Alt - Hamburg heute in Wort und Bild. Hamburg: Georg Toepffer, 1938.

FRANCÉ, Raoul Heinrich. Lebenswunder der Tierwelt: eine Tierkunde für Jedermann. Berlin: Deutscher Verlag, 1940. (margin.)

FREUD, Sigmund. Totem et tabou. Interpretation par la psychanalyse de la vie sociale des peuples primitifs. Tradução de Samuel Jankélévitch. Paris: Payot, 1947.

FREYTAG, Gustav. Der dreissigjährige Krieg. Berlin: Weltgeist, s. d.

FRIELING, Heinrich. Edle Steine: ein Kapitel aus der Mineralogie. Stuttgart: Franckh'sche Verlagshandlung, 1937.

FROHBERG, Wolfgang Otto. Brasilianisch-Portugiesisch; praktisches Lehrbuch für den Selbstunterricht; neue leichtverständliche Aussprache-Darstellung, grammatische Grundbegriffe; dem brasilianischen leben entnommener Übungsstoff mit Schlüssel, Gespräche des Alltags, kaufmännischer Briefstil, Wörterverzeichnis; Leitfaden, in kurzer Zeit ohne Lehrer die Sprache Brasiliens richtig zu beherrschen. Berlin-Dahlen: Schultze, 1938.

(Der) Froschmäusekrieg: Batrachomyomachia. Tradução de Thassilo von Scheffer. München: Heimeran, 1941. (margin.)

FUCHS, Paul. Russische Konversations-Grammatik zum Schul-, Privat- und Selbstunterricht. Heidelberg: J. Groos, 1938.

GARVENS, Erwin. Der fröhliche Jungfernstieg. Hamburger Anekdoten. Berlin: Kiepenheuer, 1940.

GASTER, Bernhard. Noveau dictionnaire des langues française et allemande. Berlin/Schöneberg: Langenscheidt, 1930.

GILBERT, Gustave. Le journal de Nuremberg. Paris: Flammarion, 1948. (margin.) 
GOETHE, J. W. von. Balladen. Leipzig: Griffel, 1925.

GOETHE, J. W. von. Briefwechsel zwischen Goethe und Zelter in den Jahren 1799 bis 1832. Ludwig Geiger (org.). Leipzig: Reclam, 1902.

GOETHE, J. W. von. Conversations de Goethe avec Eckermann. Tradução de Jean Chuzeville. Paris: Gallimard, 1949.

GOETHE, J. W. von. Faust. Texto alemão acompanhado da tradução de Gérard de Nerval. Paris: Joseph Gilbert, s. d.

GOETHE, J. W. von. Faust. Deuxième partie. Tradução de Henri Lichtenberger. Paris: Aubier, s. d. (margin.)

GOETHE, J. W. von. Gedichte. München: Wilhelm Goldmann, 1958.

(Mit) Goethe durch das Jahr. Ein Kalender für das Jahr 1951. Zürich: Artemis, 1951. (margin.)

GOETHE, J. W. von. Goethes Gedichte. Auswahl. Rudolf Franz (org.). Bielefeld/Leipzig: Velhagen \& Klasing, 1923.

GOETHE, J. W. von. Italienische Reise. Theodor Friedrich (org.). Leipzig: Reclam, s. d. (margin.)

GOETHE, J. W. von. Maximes et réflexions. Tradução de S. Sklower. Paris: Brockhaus/Avenarius, 1842.

GOETHE, J. W. von. Souvenirs de ma vie. Poésie et vérité. Tradução de Pierre du Colombier. Paris: Aubier, 1941. (margin.)

GÖTZ, Wilhelm; KOSCH, Alois. Was fliegt denn da? Tabelle zur Bestimmung der Vögel Mitteleuropas von Wilhelm Götz und Alois Kosch. Stuttgart: Franckh'sche Verlagshandlung, 1936. (margin.)

GRACIÁN Y MORALES, Baltasar. Hand-Orakel und Kunst der Weltklugheit. Tradução de A. Schopenhauer. Berlin: Deutsche Bibliothek, s. d. (margin.)

GRIMM (Brüder). Märchen. Leipzig: Reclam, 1937.

GRIMMELSHAUSEN, Hans Jakob C. von. Der abendteuerliche Simplicissimus. Eine Auswahl des Urtextes von 1669. W. Hofstaetter (org.). Stuttgart: Reclam, 1950.

GRONE, Heinrich. Kleine Sternkunde für Anfänger auf 6 Postkarten. Hamburg: Otto Meissner, 1931.

GRUBER, Arthur. Federzeichnen. Eine Anleitung für Anfänger und Freunde des Zeichnens mit der Feder. Ravensburg: Otto Maier, 1940.

GUDERIAN, Heinz. Panzer líder. A verdadeira história dos Panzers e a sua influência na Segunda Guerra Mundial. Rio de Janeiro: Biblioteca do Exército, 1966. (margin.)

GUILLAUME, Augustin. La guerre germano-soviétique: 1941-1945. Paris: Payot, 1949. (margin.)

GUIMARÃES, Maria Azambuja de Alencastro. Die brasilianische Geschichte. Ein Abriss. Tradução de Hans Jürgen Horch. Rio de Janeiro: Brasilianisches Ministerium für Auswärtige Angelegenheiten, 1952.

GUNDERT, Wilhelm; SCHIMMEL, Annemarie; SCHUBRING, Walther (eds.). Lyrik des Ostens. München: Hanser, 1958.

GUNDOLF, Friedrich. Goethe. Tradução de Jean Chuzeville. Paris: Grasset, 1932. (margin.) 
GUNNARSSON, Gunnar. Advent im Hochgebirge. Tradução de Helmut de Boor. Stuttgart: Reclam, 1951.

GÜNTHER, Hans F. K. Kleine Rassenkunde des deutschen Volkes. Berlin: J F. Lehmanns, 1937.

HAGENBECK, Carl. Von Tieren und Menschen. Berlin: Vita, 1908.

HAGENBECK, Carl. Führer durch Carl Hagenbecks Tierpark. Hamburg-Stellingen. Hamburg: Carl Hagenbecks Tierpark, 1940. (margin.)

HALLIER, Emil. Metoula-Sprachführer. Japanisch. Berlin/Schöneberg: Langenscheidt, 1913.

HÄMÄLÄINEN, Armas. Langenscheidts Reise Dolmetscher. Finnisch. Berlin/Schöneberg: Langenscheidt, 1934.

Hamburg. Kleine Ausgabe. Berlin: Grieben, 1939.

Hansestadt Hamburg und ihre beliebtesten Ausflugsziele. Kiel: A. Burkhardt, s. d.

HARDER, Ernst. Kleine Arabische Sprachlehre. Heidelberg: J. Groos, 1938.

HARTLAUB, G. F. Gustave Doré. Leipzig: Klinkhardt \& Biermann, 1923.

HAUG, Hans. Grünewald (Mathis Nithart). Paris: Braun, s. d.

HAUSENSTEIN, Wilhelm. Das Land der Griechen. Fahrten in Hellas. Frankfurt a. M.: Societät, 1934.

HEBBEL, Christian Friedrich. Eine Autobiographie nach Tagebüchern und Briefen. Introdução e notas de Willibald Klinke. Zürich: Manesse, 1945.

HEGEL, G. W. F. Esthétique. Tradução de J. G. Paris: Aubier, 1944.

HEICHEN, Walter (org.). Die Entscheidungsschlachten der Weltgeschichte von Marathon bis Tsushima. Ein Buch vom Ringen der Völker um die Machtstellung in alter und neuer Zeit. Altenburg: Geibel, 1915. (margin.)

HEIMERAN, Ernst; HOFMANN, Michel. Antike Weisheit. Eine Sammlung lateinischer und griechischer Gedanken. München: Heimeran, 1939.

HEINE, Heinrich. Italien. Hartwig Jess (org.). Leipzig: Reclam, s. d. (margin.)

HEINROTH, Oskar. Aus dem Leben der Vögel. Berlin: Julius Springer, 1938.

Heiterer Olymp. Gezeichnet von Fr. Bilek. Beschrieben von Peter Simpel. Stuttgart: W. Spemman, 1940.

Helmbrecht. Le fermier. (Meier Helmbrecht.) Tradução de André Moret. Paris: Aubier, 1938.

HELWIG, Paul. Charakterologie. Leipzig/Berlin: Teubner, 1936.

HENTSCHEL, Ernst. Das Leben des Weltmeeres. Berlin: Julius Springer, 1929. (margin.)

HERDER, J. G. von. Journal de mon voyage en l'an 1769. Tradução de Max Rouché. Paris: Aubier, 1942.

HESSE, Otto Ernst. Der Abschied. Vier Novellen um Kant. Königsberg: Gräfe \& Unzer, 1928.

HILTY, Carl. Glück. Leipzig: Huber, 1922. (margin.)

Historische Gemälde. Eine Sammlung meisterhafter Novellen und Erzählungen. (C. F. Meyer; Gottfried Keller; Theodor Fontane; Hans Voß; Gustav Freytag.) Berlin: Weltgeist, s. d.

HOFFMANN. E. T. A. Erzählungen. München: Holbein, s. d. 
HOMER. Ilias. Tradução de Thassilo von Scheffer. Leipzig: Dieterich'sche Verlagshandlung, 1938. (margin.)

HOMER. Odyssee. Tradução de J. H. Voss. Berlin: Tempel, s. d.

HUNGERLAND, Helmut. Sugestões para a crítica de arte e outros ensaios. Tradução de Catharina Baratz Cannabrava. Rio de Janeiro: MEC, 1959.

HURET, Jules. Em Allemagne. De Hamburg aux marches de Pologne. Paris: Charpentier, 1908.

HUTER, Carl. H. Das Gesicht und sein Geheimnis. Handbuch der Menschenkenntnis. Ausdruck und Charakter in der menschlichen Gestalt. Dresden: Huter, 1939.

IBSEN, Henrik. Brand. Tradução de L. Passarge. Leipzig: Reclam, s. d.

IBSEN, Henrik. Der Bund der Jugend. Tradução de Wilhelm Lange. Leipzig: Reclam, s. d.

IBSEN, Henrik. Das Fest auf Solhaug. Tradução de Emma Klingenfeld. Leipzig: Reclam, s. d.

IBSEN, Henrik. Die Frau vom Meer. Tradução de M. von Borch. Leipzig: Reclam, s. d.

IBSEN, Henrik. Kaiser und Galiläer. Tradução de Ernst Brausewetter. Leipzig: Reclam, s. d.

IBSEN, Henrik. Die Komödie der Liebe. Tradução de Philipp Schweitzer. Leipzig: Reclam, s. d.

IBSEN, Henrik. Nora oder ein Puppenheim. Tradução de Wilhelm Lange. Leipzig: Reclam, s. d.

IBSEN, Henrik. Nordische Heerfahrt. Tradução de M. von Borch. Leipzig: Reclam, s. d.

IBSEN, Henrik. Peer Gynt. Tradução de L. Passarge. Leipzig: Reclam, s. d.

IBSEN, Henrik. Rosmersholm. Tradução de A. Zinck. Leipzig: Reclam, s. d.

IBSEN, Henrik. Die Stützen der Gesellschaft. Tradução de Wilhelm Lange. Leipzig: Reclam, s. d.

IBSEN, Henrik. Die Wildente. Tradução de Ernst Brausewetter. Leipzig: Reclam, s. d.

Illustrierte Führer Baden-Baden und Umgebung. Baden-Baden: Brodesser, s. d.

ITALIAANDER, Rolf. Immer wenn ich unterwegs bin. Verse und kleine Prosa. Wien: Mundus, 1962.

JACKSON, Hiram. Ausführliche Anleitung zum Hypnotismus, Mesmerismus, Hellsehen, suggestiver Therapeutik und der Erziehung im Schlafzustande. Berlin: Psychologischer Verlag, s. d.

JAHN, Johannes. Wörterbuch der Kunst. Stuttgart: Kröner, 1940.

JASPERS, Karl. Introduction à la philosophie. Tradução de Jeanne Hersch. Paris: Plon, 1951.

JASPERS, Karl. Vernunft und Existenz. Fünf Vorlesungen. Bremen: Storm, 1949.

JEAN PAUL. Vie de Fixlein. Régent de cinquième. Tradução de Pierre Velut. Paris: Aubier, 1943.

JEAN PAUL. Voyage du proviseur Fälbel. Vie de Maria Wutz. Tradução de Geneviève Bianquis. Paris: Aubier, 1930. (margin.)

JENSEN, Johannes Vilhelm. Der Monsun und andere Tiergeschichten. Berlin: Fischer, 1925. 
JUNG, C. G. Aspects du drame contemporain. Tradução de R. Cahen-Salabelle. Paris: Vendôme, 1948. (margin.)

JÜNGER, Ernst. Journal I: 1941-1943. Paris: René Juliard, 1951. (margin.)

KAFKA, Franz. Le procès. Tradução de Alexandre Vialatte. Paris: Gallimard, 1953. (margin.)

Kalewala. Das Heldenlied des finnischen Volkes. Erzählt von Arthur Luther. Leipzig: Esche, 1936.

KALTHOFF, Henrique. Punhos de Berlim às margens do Reno e Ruhr: breve história da evolução prussiano-alemã nos últimos 150 anos, vista por um renano. São Paulo: Cupolo, 1946.

KANT, Immanuel. Extraits. Caire: Institut Français, 1945.

KARUTZ, Richard; KRAEMER, Augustin. Die Völker Nord- und Mittel- Asiens. Stuttgart: Franckh'sche Verlagshandlung, 1925.

KEMPEN, Thomas von. Imitatio Christi. Das Buch von der Nachfolge Christi. Franz Keller (org.). Freiburg im Breisgau: Herderische Verlagshandlung, 1938. (margin.)

KEYSERLING, H. Alexander von. Le monde qui nait. Tradução de Christian Sénéchal. Paris: Stock, 1929.

KEYSERLING, H. Alexander von. Das Reisetagebuch eines Philosophen. Darmstadt: Otto Reichl, 1921. (margin.)

KLEIN, Hans W. 1000 idiomatische französische Redensarten mit Erklärungen und Beispielen. Berlin/Schöneberg: Langenscheidt, 1937.

KLEIST, Heinrich von. Die Hermannsschlacht. Ein Drama in fünf Aufzügen. Leipzig: Reclam, s. d.

KLÖS, Heinz-Georg. Wegweiser durch den Zoologischen Garten Berlin. Berlin: Aktien-Verein des Zoologischen Garten, 1962.

KOOP, Hugo. Über die Lehrbarkeit der Tugend. Untersuchungen zum platonischen und nachplatonischen Problem des Lehrens und Lernens. Würzburg: K. Triltsch, 1940.

Kopenhagen und Umgebung. Berlin: Grieben, 1935. (margin.)

$\mathrm{KOSCH}$, Alois. Was ist das für ein Baum? Tabelle zum Bestimmen von über 300 wichtigen Bäumen und Sträuchern. Stuttgart: Franckh'sche Verlagshandlung, 1938.

KRAUSE, Konrad. Werkstatt der Wortkunst. Eine Poetik in Selbstzeugnissen deutscher Dichter. Berlin/München: Oldenbourg, 1942.

KRUG, Wilhelm. 1000 Verse. Berlin: Schützen, 1940.

KRÜGER, Wilhelm. Unser Pferd und seine Vorfahren. Berlin: Julius Springer, 1939.

KÜKELHAUS, Heinz. Thomas le pêcheur de perles. Tradução de Jeanne FournierPargoire. Paris: Albin Michel, 1949.

KÜMMEL, Otto. Die Kunst Ostasiens. Berlin: Cassirer, 1934.

Kurzer Führer durch das Goethehaus und das Goethe-Nationalmuseum. Weimar, 1938.

KUSMIN, Michail Alexeievitch. Alexandrinische Gesänge. Tradução de Alexander Eliasberg. München: Musarion, 1921.

LAFUE, Pierre. Histoire de l'Allemagne. Paris: Flammarion, 1950. (margin.) 
Bonomo, D. R. - A biblioteca alemã

LAMMEYER, Joseph. Metoula-Sprachführer. Arabisch (Syrisch). Berlin/Schöneberg: Langenscheidt, 1913.

LANG, Martin (org.). Kleines Lesebuch. Stuttgart: Deutsche Verlags-Anstalt, 1948.

LANGE, Johannes. Kurzgefasstes Lehrbuch der Psychiatrie. Leipzig: Georg Thieme, 1939.

LÂO-TSE. Taoteking. Das Buch des Alten von Sinn und Leben. Tradução de Richard Wilhelm. Düsseldorf/Köln: Eugen Diederich, 1957.

Leitfaden zur praktischen Erlernung des Billardspiels. Neurode: Ed. Rose, 1908.

LESSING, G. E. Nathan der Weise. Ein dramatisches Gedicht in fünf Aufzügen. Leipzig: Reclam, 1941.

LEWINSOHN, Richard. Eine Geschichte der Tiere. Ihr Einfluss auf Zivilisation und Kultur. Hamburg: Rowohlt, 1952.

LEYST, Gerhard. 1000 Wörte Russisch. Berlin: Ullstein, 1936.

LOETSCHER, Hugo. Abwässer. Ein Gutachten. Zürich: Arche, 1963.

London. Berlin: Grieben, 1938. (margin.)

LORENZ, Günther. Federico García Lorca. Karlsruhe: Rowohlt, 1963.

LORENZ, Günther. Literatur in Lateinamerika. Zürich: Galerie, 1967.

LUDWIG, A. Aussaat. Deutsches Lesebuch für höhere Schulen. Erste Abteilung. Berlin: G. Grote'sche Verlagsbuchhandlung, 1931.

LUDWIG, A. Aussaat. Deutsches Lesebuch für höhere Schulen. Siebente Abteilung. Berlin: G. Grote'sche Verlagsbuchhandlung, 1933.

Lufthansa Travel Guide. Südamerika/South America/Amérique du Sud. Hamburg: Nagel, 1962.

LUTHER, Martin. Sendbrief vom Dolmetschen und vier andere Schriften weltlichen Inhalts. Leipzig: Reclam, 1938.

MADÁCH, Imre. Die Tragödie des Menschen. Tradução de Eugen Planer. Halle a. d. S.: Otto Hendel, 1891.

MAJER, Beniamin. Neuer praktischer Führer von Florenz und Umgegend. Rom/Mailand/Venedig: Scrocchi, s. d.

MANN, Thomas. Bekenntnisse des Hochstaplers Felix Krull. Frankfurt: Fischer, 1955.

MARAIS, Eugène Nielen. Die Seele der weissen Ameise. Berlin: Herbig, 1939.

Marginalien zu J. G. Rosa: Grande Sertão. Köln: Kiepenheuer \& Witsch, 1964.

MARTIALIS, Marcus Valerius. Martials Sinngedichte. Tradução de Horst Rüdiger. München: Heimeran, s. d.

MASPERO, Gaston C. C. Geschichte der Kunst in Ägypten. Stuttgart: Julius Hoffman, 1925.

MAUTHNER, Fritz. Wörterbuch der Philosophie. Leipzig: Felix Meiner, 1923-24.

MEISSNER, Carl. Phraséologie latine. Tradução de Charles Pascal. Paris: Klincksieck, 1942.

MENGE, Herman. Langenscheidts Taschenwörterbuch der griechischen und deutschen Sprache. Berlin/Schöneberg: Langenscheidt, 1910.

MEYRINK, Gustav. Der Golem. Leipzig: Kurt Wolff, 1916.

MEYRINK, Gustav. La notte di Valpurga. Milano: Fratelli Boca, 1944. 
MICHAELIS, H. Novo diccionario da lingua portugueza e allemã enriquecido com os termos technicos do commercio e da industria, das sciencias e das artes e da linguagem familiar. Leipzig: Brockhaus, 1923.

MICHAUD, Régis. Die amerikanische Literatur der Gegenwart. Tradução de Käthe Illch. Leipzig: Dioskuren, 1931. (margin.)

MIETHE, Adolf. Unter der Sonne Oberägyptens. Neben den Pfaden der Wissenschaft. Berlin: Reimer, 1924.

(Die) Minnesinger in Bildern der Manessischen Handschrift. Leipzig: Insel, s. d.

MOHR, Adrian. Deutschland. Ein Bildwerk. München: Ludwig Simon, s. d.

MÖLLER, Vera. Klein Erna. Ganz dumme Hamburger Geschichten. Hamburg: Hans Christian, s. d.

MORGENSTERN, Christian. Alle Galgenlieder. Leipzig: Insel, 1940.

MÜSELER, Wilhelm. Reitlehre. Berlin: Paul Parey, 1936.

NAVARRE, Marguerite de. Das Heptameron. Die Erzählungen der Königin von Navarra. Lübeck/Leipzig: Antäus, 1939.

NEUMANN, Adolpho. Nova grammatica alemã, theorica e pratica, segundo o systema de Emilio Otto. Rio de Janeiro: Francisco Alves, s. d.

NEURAUTER, Nivard. Ohne Gott - Ohne Glück. Geschichte der Katholischen Kirche mit Sonderteil zum Anno Santo 1950. Wagner, 1949.

NEUNTEUFEL, Adolf. Yasi-Yateré. Acht Jahre Tierfang und Jagd im Urwald von Paraguai. Leipzig: Brockhaus, 1941. (margin.)

NIETZSCHE, F. W. Humain, trop humain. Première partie. Vols. I e II. Tradução de A. M. Desrousseaux. Paris: Mercure de France, 1941. (margin.)

NIETZSCHE, F. W. Le voyageur et son ombre. Humain, trop humain. Deuxième partie. Tradução de Henri Albert. Paris: Mercure de France, 1943. (margin.)

NIETZSCHE, F. W. Pages choisies. Tradução de Henri Albert. Paris: Mercure de France, 1947. (margin.)

NIETZSCHE, F. W. Par delà le bien et le mal. Tradução de Henri Albert. Paris: Mercure de France, 1948. (margin.)

NOSSACK, Hans Erich. Interview avec la mort. Tradução de Denise Naville. Paris: Gallimard, 1950.

NOVALIS. Henri d'Ofterdingen. Tradução de Marcel Camus. Edição bilíngue. Paris: Aubier, s. d. (margin.)

NOVALIS. Hymnen an die Nacht. Die Christenheit oder Europa. Wiesbaden: Insel, 1950.

NOVALIS. Petits écrits. Tradução de Geneviève Bianquis. Edição bilíngue. Paris: Aubier, 1947. (margin.)

ORTEGA Y GASSET, José. Buch des Betrachters. Helene Weyl (org.). Stuttgart/Berlin: Deutsche Verlags-Anstalt, s. d.

ORTEGA Y GASSET, José. Stern und Unstern. Gedanken über Spanien Landschaft und Geschichte. Helene Weyl (org.). Stuttgart/Berlin: Deutsche VerlagsAnstalt, s. d.

OTTO, Emilio. Gramática elemental de la lengua alemana. Heidelberg: J. Groos, 1911. 
PESCHEL, Oskar. Geschichte der Erdkunde bis auf A. v. Humboldt und Carl Ritter. München: J G. Cotta'sche Buchhandlung, 1865.

PETERICH, Eckart. Kleine Mythologie - die Götter und Helden der Griechen. Frankfurt am Main: Societät, 1937.

PETERS, Ludwig. 30 Stunden Finnisch für Anfänger. Berlin/Schöneberg: Langenscheidt, 1940.

PETERSEN, Georg Paysen. Till Eulenspiegels lustige Streiche. Stuttgart: Ferdinand Carl, s. d.

PETRICONI, H. Die spanische Literatur der Gegenwart seit 1870. Wiesbaden: Dioskuren, 1926.

PETRONIUS. Das Gastmahl des Trimalchio. Nach dem Satiricon des Petronius. Tradução de Wilhelm Heinse. Düsseldorf: Ernst Ohle, 1913.

PIPER, Reinhard. Das Tier in der Kunst. München: Piper, 1910.

PLAUT, Hermann. Japanische Konversations-Grammatik mit Lesestücken und Gesprächen. Heidelberg: J. Groos, 1936.

PLOETZ, Karl. Auszug aus der alten, mittleren, neueren und neuesten Geschichte. Berlin/Leipzig: Ploetz, 1938.

PODHAJSKY, A. Die spanische Reitschule. Wels: Welsermühle, 1953.

POHL, Johann Baptist Emanuel. Viagem no interior do Brasil. Empreendida nos anos de 1817 a 1821 e publicada por ordem de Sua Majestade o Imperador da Áustria Francisco Primeiro. Tradução do Instituto Nacional do Livro da edição de Viena, 1837. Rio de Janeiro: INL, 1951.

POSSE, Hans. Die staatliche Gemäldegalerie zu Dresden. Dresden: Wilhelm und Bertha von Baensch Stiftung, 1929.

POURTALÈS, Guy de. Louis II de Bavière ou Hamlet-Roi. Paris: Gallimard, 1928.

PURZELBAUM, Peter. Der fröhliche Kommiss. Kaczmarek III. Berlin: Brunnen, 1928.

PURZELBAUM, Peter. Vom Kommiss, Kaczmarek und den Maikäfern. Berlin: Brunnen, 1926.

RAABE, Wilhelm. La chronique de la rue aux Moineaux. Tradução de Adna Lévy. Paris: Aubier, 1931. (margin.)

RAJBERTI, Giovanni. Katzen-Natur. Tübingen: Heimeran, 1941.

RAUSCHERT, Manfred. Die technischen Erfahrungen meiner Forschungsreisen in Nord-Brasilien 1954/1956 Abschlussbericht. Bonn: Schmidt \& Co., 1957.

RAUSCHERT, Manfred. Forscherfahrt zum Inini. Wien: St. Gabriel, s. d.

RAUSCHNING, Hermann. Hitler m'a dit: confidences du Führer sur son plan de conquête du monde. Paris: Cooperation, 1939. (margin.)

Republik Österreich Staatsamt für Äusseres. Diplomatische Aktenstücke zur Vorgeschichte des Krieges 1914. Ergänzungen und Nachträge zum Österreichisch-Ungarischen Rotbuch I. Teil-28. Juni bis 23. Juli 1914. Wien: Staatsdruckerei, 1919.

RICHTER, Albert; GÖRRES, Guido. Deutsche Heldensagen. Leipzig: Schmidt \& Günther, s. d.

RICHTER, Johann P. F. Vie de Fixlein. Régent de cinquième. Tradução de Pierre Velut. Paris: Aubier, 1943. 
RICHTER, Johann. P. F. Voyage du proviseur Fälbel. Vie de Maria Wutz. Tradução de Geneviève Bianquis. Paris: Aubier, 1930. (margin.)

RILKE, R. M. Die Aufzeichnungen des Malte Laurids Brigge. Leipzig: Insel, 1940.

RILKE, R. M. Cartas a um jovem poetalA canção de amor e de morte do portaestandarte Cristovão Rilke. Tradução de Paulo Rónai e Cecília Meirelles. Rio de Janeiro: Globo, 1961.

RILKE, R. M. Das Marien-Leben. Leipzig: Insel, s. d.

RILKE, R. M. Elegias de Duíno. Tradução de Dora Ferreira da Silva. São Paulo: (sem editora), 1956.

RILKE, R. M. Geschichten vom lieben Gott. Wiesbaden: Insel, 1922.

RILKE, R. M. Histoires du bon Dieu. Paris: Émile Paul Frères, 1950.

RILKE, R. M. Späte Gedichte. Leipzig: Insel, 1934.

RILKE, R. M. Stimmen der Freunde. Freiburg im Breisgau: Urban, 1931.

RILKE, R. M. Die Weise von Liebe und Tod des Cornets Christoph Rilke. Wiesbaden: Insel, 1950.

Rom und Umgebung. Berlin: Grieben, 1937. (margin.)

ROSENFELD, Anatol. Doze estudos. São Paulo: Conselho Estadual de Cultura, 1959.

ROYER, Louis-Charles. L'amour em Allemagne. Paris: Les Editions de France, 1930.

RÜDIGER, Horst (org.). Griechische Gedichte. München: Heimeran, 1939.

RÜDIGER, Horst (org.). Lateinische Gedichte. München: Heimeran, 1937.

SACHER-MASOCH, Leopold von. La pantoufle de Sapho et autres contes. Tradução de D. Dolores. Paris: Charles Carrington, 1907.

SAPPER, Agnes. Gretchen Reinwalds erstes und letztes Schuljahr. Stuttgart: D. Gundert, s. d.

SCHELER, Max F. Zur Rehabilitierung der Tugend. Zürich: Arche, 1950. (margin.)

SCHERR, Johannes. La société et les moeurs allemandes. Tradução de Victor Tissot. Paris: Dentu, 1877. (margin.)

SCHILlER, J. C. F. von. Guillaume Tell. Texto alemão. Paris: Hachette, 1900. (margin.)

SCHILLER, J. C. F. von. Wallenstein. Vol. I. Wallensteins Lager; Die Piccolomini. Stuttgart: Reclam, 1949. (margin.)

SCHILLER, J. C. F. von. Wallenstein. Vol. II. Wallensteins Tod. Paris: Hatier, 1939. (margin.)

SCHILLING, Heinar. Weltgeschichte. Ereignisse und Daten von der Eiszeit bis heute. Berlin: Weidmannsche Buchhandlung, 1933. (margin.)

Schlag nach! Wissenswerte Tatsachen aus allen Gebieten. Leipzig: Bibliographisches Institut, 1938.

SCHMID, Bastian. Zur Psychologie unserer Haustiere. Frankfurt am Main: Societät, 1939. (margin.)

SCHMIDT, Heinrich. Philosophisches Wörterbuch. Leipzig: Alfred Kröner, 1934.

SCHMIDTBONN, Wilhelm. Die siebzig Geschichten des Papageien. Leipzig: Rütten \& Loening, 1937. 
SCHOLZ, Wilhelm von. Das Buch des Lachens. Schnurren, Schwänke und Anekdoten. Berlin: Deutscher Verlag, 1938.

SCHOPENHAUER, Arthur. Aphorismen zur Lebensweisheit. Heinrich F. C. Hannsmann (org.). Stuttgart: Schuler, 1948. (margin.)

SCHREIBER, Walter T. Praktische Grammatik der altgriechischen Sprache. Mit besonderer Berücksichtigung des attischen Dialektes. Für den Selbstunterricht. Mit griechisch-deutschen und deutsch-griechischen Wörterverzeichnis. Wien/Leipzig: Hartleben, s. d.

SCHRÖDER, Werner. Das Aquarium, Terrarium und Insektarium im Zoologischen Garten Berlin. Berlin: Aktien Verein des Zoologischen Garten, s. d.

SCHUCHHARDT, Karl. Vorgeschichte von Deutschland. Berlin/München: Oldenbourg, 1935.

SCHUMANN, Otto. Meyers Opernbuch. Einführung in die Wort- und Tonkunst unserer Spielplanopern. Leipzig: Bibliographisches Institut, 1938.

SCHWANTES, M. H. Gustav. Deutschlands Urgeschichte. Leipzig: Quelle \& Meyer, 1934.

SCHWARZ, Heinrich. Langenscheidts dictionnaire de poche de langues française et allemande. Berlin/Schöneberg: Langenscheidt, 1929.

SETON, Ernest Thompson. Tiere der Wildnis. Stuttgart: Franckh'sche Verlagshandlung, s. d.

SHIRER, William L. Diário de Berlim. Jornal de um correspondente estrangeiro, 1934-1941. Tradução de M. P. Moreira Filho. Rio de Janeiro: José Olympio, 1941. (margin.)

SICK, Heinrich Helmut. A proteção das aves contra a umidade. Rio de Janeiro: Museu Nacional, 1963.

SICK, Heinrich Helmut. Sons emitidos pelas aves independentemente do órgão vocal. Caso de Conopophaga Lineata (Wied). Rio de Janeiro: Academia Brasileira de Ciências, 1965.

SICK, Heinrich Helmut. Tucaní entre los indios y los animales del centro del Brasil: relato de la primeira travesía Sudeste-Noroeste del Brasil Central. Tradução de Francisco Payarols. Barcelona: Labor, 1960.

SILESIUS, Angelus. Aus dem Cherubinischen Wandersmann und anderen geistlichen Dichtungen. Erich Haring (org.). Stuttgart: Reclam, 1950.

SILESIUS, Angelus. Pèlerin Chérubinique. Tradução de Henri Plaud. Paris: Aubier, 1946. (margin.)

SNOKO-BOROWSKY, Eugène. So darfst du nicht Schach spielen! Tradução de G. Wiarda. Leipzig: Hans Hedewigs Nachf, s. d.

SOARES, João Batista G. A. Martins. Poemas alemães. São Paulo: Martins, 1954.

Sociedade Brasileira de Romanistas. A Alemanha no coração do Brasil. Rio de Janeiro, 1964.

SOFFEL, Karl. Der Tierkreis. Das Tier in der Dichtung aller Völker und Zeiten. Berlin: Erich Reiss, s. d.

SPENGLER, Oswald. La decadencia de Occidente. Bosquejo de una morfología de la historia universal. Tradução de Manuel Morente. Madrid: Espasa-Calpe, 194042. (margin.) 
SPENLÉ, Jean-Édouard. La pensée allemande de Luther à Nietzsche. Paris: Armand Colin, 1949. (margin.)

SPRINGER, Anton Heinrich. Handbuch der Kunstgeschichte. Leipzig: Alfred Kröner, 1918-20.

Staatliche Gemäldegalerie, Dresden. Katalog der alten Meister. Dresden/Berlin: Wilhelm und Bertha von Baensch Stiftung/Julius Bard, 1930.

STAËL-HOLSTEIN, Anne-Louise-Germaine Necker, baronesa de. De l'Allemagne. Vol. I. Paris: Flammarion, s. d. (margin.)

STAMMLER, Wolfgang. Alte deutsche Tierfabeln. Jena: Eugen Diederich, 1926.

STEHLI, Georg Jakob. Welches Tier ist das? Tabellen zum Bestimmen der wildlebenden Säugetiere, Kriechtiere und Lurche Grossdeutschlands. Stuttgart: Franckh'sche Verlagshandlung, 1940.

STEMPLINGER, Eduard. Von berühmten Ärzten. 202 Anekdoten aus authentischen Quellen gesammelt. München: Piper, 1938.

Stockholm und Umgebung. Berlin: Grieben, 1933.

STORM, Theodor. Der Schimmelreiter. Walther Herrmann (org.). Stuttgart: Reclam, 1949.

STRAGANZ, P. M. Illustrierte Weltgeschichte der neuesten Zeit. Von der grossen französischen Revolution (1789) bis vor dem Ausbruch des Weltkrieges. München: Allgemeine Verlags-Gesellschaft m.b.H., s. d.

TACITUS, Publius Cornelius. Germânia. Tradução de Sady Garibaldi. Rio de Janeiro: Para Todos, 1943.

Tausend und eine Nacht. Liebesgeschichten aus 1001 Nacht. Leipzig: Antäus, 1939.

TEMPLER, Bernhard. Grammatik der hebräischen Sprache für den Selbstunterricht. Leipzig/Wien: Hartleben, s. d.

TIBULLUS, Aulus Albius. Elegien. Tradução de Werner Fraustadt. München: Heimeran, 1940. (margin.)

TIMMERMANS, Felix. Kleine Leute in Flandern. Stuttgart: Reclam, 1949.

TRAUTNER, Hanns. Sagen vom Harz. Magdeburg: Otto Lindner, 1938.

TURNBULL, Victor. Lehrgang des persönlichen Magnetismus. Selbstbeherrschung und Charakterbildung. Berlin: Psychologischer Verlag, s. d. (margin.)

(Ein) Unterrichts-Kursus über den Heilmagnetismus in fünf Kapiteln. Berlin: Psychologischer Verlag, s. d.

V. B. Strassen. Atlas von Deutschland. München: Zentralverlag der N. S. D. A. P., 1936.

VARÉ, Daniele. Der lachende Diplomat. Berlin: Paul Zsolnay, 1940.

VAVRINA, Fritz. Metoula-Sprachführer. Arabisch (Ägyptisch). Berlin/Schöneberg: Langenscheidt, 1916.

VOLZ, Hans. Daten und Geschichte der N.S.D.A.P. Berlin/Leipzig: Ploetz, 1938.

WAETZOLDT, Wilhelm. Du und die Kunst. Eine Einführung in Kunst. Berlin: Deutscher Verlag, 1938.

WAGNER, Richard W. Das Rheingold. Mainz: B. Schott's Söhne, s. d.

WAGNER, Richard W. Das Rheingold. Leipzig: Reclam, 1937. (margin.)

WASSERZIEHER, Ernst. Leben und Weben der Sprache. Berlin/Bonn: Dümmler, 1935. 
Bonomo, D. R. - A biblioteca alemã

WASSERZIEHER, Ernst. Sprachgeschichtliche Plaudereien. Berlin/Bonn: Dümmler, 1930.

WERFEL, Franz. Die vierzig Tage des Musa Dagh. Berlin: Paul Zsolnay, 1933.

WIDMANN, Walter. Welcher Stern ist das? 48 ganzseitige Sternkarten mit einer Tabelle zum Bestimmen der Sternbilder in allen Jahreszeiten, mit sieben Farbtafeln und zahlreichen Textbildern. Stuttgart: Franckh'sche Verlagshandlung, 1939.

WIDMANN, Walter. Welcher Stern ist das? 60 Sternkarten mit einer Tabelle zum Bestimmen der Sternbilder in allen Jahreszeiten und einer kurzen Einführung über unser Wissen von den Sternen. Stuttgart: Franckh'sche Verlagshandlung, 1952.

WILD, Friedrich. Die Englische Literatur der Gegenwart seit 1870. Drama und Roman. Wiesbaden: Dioskuren, 1928.

WILD, Friedrich. Die Englische Literatur der Gegenwart seit 1870. Versdichtungen. Leipzig: Dioskuren, 1931.

WILDERMANN, Hans. Die Geschichte von der keuschen Susanna Juda und Thamar. München: Waldhauss, s. d.

WILLENS, Emilio. A aculturação dos alemães no Brasil. Estudo antropológico dos imigrantes alemães e seus descendentes no Brasil. São Paulo: Ed. Nacional, 1946.

WINTER, Nevin Otto. Die Elbe: das Ein- und Ausgangstor Deutschlands. Berlin: Dietrich Reimer, 1934. (margin.)

WOLF, Werner. Kleine schwedische Sprachlehre. Heidelberg: J. Groos, 1938.

WÖLFFLIN, Heinrich. Principles of art history: the problem of the development of style in later art. Tradução de M. D. Hottinger. New York: Dover, s. d.

WYKEHAM, Reginald. 1000 idiomatische englische Redensarten. Berlin/Schöneberg: Langenscheidt, 1936.

Zeichner machen Witze. Frankfurt am Main: Societät, 1941.

ZUKOWSKY, Ludwig. Aus Wald und Flur. Tiere unserer Heimat. Hamburg: Cigaretten-Bilderdienst, 1938.

Recebido em 10/10/2010

Aprovado em 31/10/2010 